\title{
Monitoring and Logistics of Erection of Prefabricated Modular Buildings
}

\author{
Sergei Sychev* and Diana Sharipova
}

Saint Petersburg State University of Architecture and Civil Engineering, St. Petersburg - 190005, Russia; sasychev@ya.ru

\begin{abstract}
Prefabricated buildings and structures are mounted from uniform prefabricated three-dimensional units, providing strength, preset thermal properties of structures, dynamic stability, immutability of geometric dimensions of the prefabricated elements during their manufacture, transportation, and installation in special and difficult conditions. A three-dimensional unit is a combined system, comprehensively elaborated by technologists, designers, and constructors, the parameters of which are optimized in terms of manufacturability, transportation, installation, dismantling, convenience, and safety of the buildings. The multi-factor model of the system was built under the condition of minimizing the reduced costs, labor input, transportation, and erection of buildings. Methods of projects monitoring are linked to the analysis of transport schemes of delivery and installation of modules with the choice of parameters of the jib crane at erection of transformable buildings. The options of transport schemes (road, rail, water - ferry, air - helicopter and airship) have also been considered. The choice of transportation means is defined by the range of transportation and estimated relative values of the labor input, the cost and duration of transportation and installation of modules.
\end{abstract}

Keywords: Construction, High-speed Modular Buildings, Modules, Prefabricated, Prefabricated Blocks, Room Units, Transformable

\section{Introduction}

Development of industrial low-rise construction can be successfully accomplished by the use of highly prefabricated modular buildings with improved thermal and performance characteristics.

Prefabricated Modular Buildings (PMB) are buildings mounted from three-dimensional uniform elements - prefabricated modules - including internal engineering equipment, providing for the preset physical and mechanical properties of the structures, stability, stiffness, strength, immutability of geometric dimensions of modules during transportation and installation.

A PMB system is a brand new concept of prefabricated modular erection of low-rise residential houses up to three floors, as well as industrial buildings from threedimensional modules. The basis of the study was the implementation of continuous monitoring of PMB at various stages of construction.
A three-dimensional module is a combined system, comprehensively elaborated by technologists, architects, designers, constructors, and other specialists, which optimally takes into account the factors of cost saving, manufacturability, transportation, installation, dismantling, safety and convenience of operation. PMB structures made of three-dimensional modules of various types and modifications are made by the industrial method, including the "sandwich" type or combined structures that is dictated by the variability of construction projects and regulatory requirements for technological and design solutions, as well as for thermal indicators. Stationary PMB for prefabricated construction should have a guaranteed service life of 55-60 years.

The initial indicators include weight, dimensions, the number of modules, the number of standard sizes, materials consumption. The key indicators include the duration of transportation and installation, the work volume and labor input, and the reduced costs. Comparison of the

${ }^{*}$ Author for correspondence 
works variants at the stages of the technological cycle was performed based on specific reduced costs, the prime cost and duration of work. Auxiliary indicators (the mechanization level, the shift index, the workability of industrial products and processes, the extent of work mix, the downtime, the workers' skills, etc.) were taken into account for the specific conditions of the construction.

The multifactor mathematical model of the system of technical and economic indices of PMB was built based on the condition of minimization of the generalized indicator, which takes into account the reduced costs, the buildings fabrication, transportation, and installation labor input.

\section{Methods of Monitoring the Pmb Erection and Operation}

A comparative analysis of the transport schemes of delivery and installation of modules and the technique and algorithm of the jib crane parameter selection at PMB installation is provided. A comparative analysis of the options of transport schemes used in the delivery of modules from the factory to the erection site is provided. Herewith, variants of transport schemes were considered, which combine different transport modes (road, rail, water-ferry, air-helicopter and airship). The choice of transportation means is defined by the range of transportation and estimated relative values of the labor input, the cost and duration of modules' transportation.

Based on the analysis of the transport schemes of the block modules delivery, we identified the preferred options and developed a diagram for the selection of optimal solutions. Herewith, the transportation of modules with an airship of the "flying crane" type was proposed and justified for special conditions of PMB. The issue of choosing a rational load-lifting means to perform loading and unloading operations during transportation was also considered. The basic criteria for the optimization of production processes were determined, and the graphs, allowing choosing a rational variant of performance of works for various schemes of modules transportation (manufacturing plant - plant storage - interim storage site storage - site) were drawn. The transport schemes (1 - road (car); 2 - road-rail; 3 - road - rail - ferry - road; 4 - road - ferry - road; 5 - road - air (helicopter) - road; 6 - air (airship)) were analyzed by the following parameters: the unit labor costs of one module transportation; the cost and duration of one module transportation. The most rational scheme for transportation to the distance up to $10,000 \mathrm{~km}$ is scheme 1 , and for more than $10,000 \mathrm{~km}$ schemes 5 and 6 (in extreme and special circumstances of rapid construction).

Based on the analysis of the indicators of the transport schemes practically implemented, it was found that in a significant number of cases, above-norm time was spent by modules and other PMB components in transit, as well as in warehouses of various levels. This was due to the lack of a clear coordination between the timing of the delivery of structures and products and the installation works' commencement, and due to the transportation failures. Some sites faced sufficiently long periods of construction downtime or its insufficient intensity (Table 1).

Table 1. Organization of the erection process

\begin{tabular}{llccc}
\hline Indicator & Unit of mea- & \multicolumn{3}{c}{ Construction projects } \\
\cline { 3 - 5 } description & surement & Gabrolovo & Pushkin & Siversky \\
\hline Transit time & Days & $16-180$ & $12-79$ & $7-69$ \\
Stock time & Days & $1-224$ & $1-214$ & $1-265$ \\
Installation & Days & $51-259$ & $30-145$ & $35-258$ \\
time & & & & \\
\hline
\end{tabular}

An analysis showed that PMB erected from modules and other elements that had had a significant delay between the shipment from the plant and the completion of the building erection, had a significant risk of certain failures of the structures, which usually occur during the periods of seating and normal operation of houses.

The study of this issue showed that the main causes of the defects are: excessive hydration of structures (mold on walls, icing in winter), appearance of mechanical defects (cracks, deformation), and change in the geometrical parameters of structural elements (both along the perimeter, and on the plane). It was shown that to ensure the required quality of PMB construction and to avoid unnecessary costs for the elimination of defects in the process of construction and operation, the transportation system "factory-site" and the organization of the construction process should not allow unnecessary "lying long" of structures and interruption of the installation work.

The section contains the developed technique and algorithm for selecting the jib crane parameters for the $\mathrm{PMB}$ erection from modules by the technical parameters of the crane (jib length, lift height, outreach). Depending on the construction site conditions, we considered the one-sided and double-sided erection diagrams. 
Generalized performance characteristics of reliability of modular buildings can be estimated using the generalized (integrated) coefficient $K_{n,}$ which is defined by the formula:

$K_{n}=\sum_{i=1}^{m} K_{i} a_{i} / m$

where $a_{i}$ is the weighting coefficient of the PMB element;

$m$ is the number of these elements in the system (the building or complex of buildings);

$K_{i}$ is the $i$-th element's reliability coefficient.

$K_{i}=\frac{\left(1-F_{k} / 100\right)}{\grave{O}_{s}} \cdot T_{r l}$

where $T_{s}$ is the PMB service life,

$T_{r l}$ is the residual service life of the building after $t$-period of its operation.

The probability of failure-free operation of the project can be determined by the formula:

$P_{i}=e^{-\lambda t}$

where $\lambda$ is the failure rate; $t$ is the operation time.

The service life (durability) of the project:

$K_{D}=T_{r l} / T_{s}$

$K_{D}$ is the coefficient of PMB durability.

\section{Results and Discussion}

It was determined that at erection of modular buildings, the labor input and duration of works are influenced by the weight and completeness of units, their joining methods, the design of joints and nodes of connections.

\subsection{Analysis of Defects of PMB Modules Installation}

With the known precision of parts manufacturing, the technological tolerances for the marking works and installation of structures should be calculated by the accuracy ratio $\mathrm{K}_{\mathrm{AV} \text { : }}$

$K_{A V}^{2}=\left(\Delta_{\Sigma}^{2}-\sum_{i=1}^{n-1} \Delta_{i k}^{2}\right) / \sum_{i=1}^{n-1}\left(I_{i M}^{2}+I_{i I}^{2}\right)$ where $I_{M}$ and $I_{I}$ are the units of tolerance, respectively, for the marking works and structures installation; $\Delta_{\mathrm{k}}$ is the known tolerances for parts manufacturing, provided at this stage of outfit operation.

Complete assemblability of PMB with the required precision of installation of modules is determined by the ratio:

$\Delta_{a} \geq \Delta_{\Sigma}$

where $\Delta_{a}$ is the actual value of tolerance; $\Delta_{\Sigma}$ is the total tolerance.

Herewith:

$\Delta_{\Sigma}=\sqrt{\sum_{i=1}^{n} \Delta_{i}^{2}}$,

where $\Delta_{i}$ is the value of $i$-th tolerance;

$n$ is the number of technological tolerances that affect the installation accuracy.

To calculate the accuracy of the PMB erection, the values of errors of three groups were determined: at the manufacture of modules, at the geodetic marking work, and at the installation of elements. The actual size errors and deviations of elements at installation must not exceed the standard parameters of accuracy:

$\delta_{i}^{a}=\sqrt{\delta_{m}^{2}+\delta_{d}^{2}} \leq \delta_{i}^{n}$,

where $\delta_{i}^{a}$ is the actual deviations at installation;

$\delta_{m}$ are errors during modules installation;

$\delta_{d}$ are errors caused by deformation of structures of the building as a result of the force appliance at installation; $\delta_{i}^{n}$ is the standard deviation at installation.

The pilot work confirmed that during the remote control of the erection crane, equipped with the jig-step mechanism and rigid cross frame, the mounting cycle time is reduced by 1.5 times and the productivity of the crane is increased by $40-60 \%$. The comparative technical and economic indicators of various methods of modules installation are presented in Table 2, which shows that depending on the method of positioning the mounted module, the free, restricted free, semi-forced and forced installation can be performed.

During the research, the authors conducted a comparative analysis of erection of buildings of different 
design systems, the results of which are shown in Table 2, which considers the following options:

Option 1 - Type "Buk"; Option 2 - type "CUB", "Neva"; Option 3 - Type "Sokol," "Modul."

Table 2. Comparative technical and economic indicators of different methods of modules installation

\begin{tabular}{lcccc}
\hline Indicators & \multicolumn{4}{c}{ Installation methods } \\
\cline { 2 - 5 } & Free & $\begin{array}{c}\text { Restricted } \\
\text { free }\end{array}$ & $\begin{array}{c}\text { Semi- } \\
\text { forced }\end{array}$ & Forced \\
\hline \multicolumn{1}{c}{ Outfit } & $\begin{array}{c}\text { flexible } \\
\text { straps }\end{array}$ & $\begin{array}{c}\text { flexible } \\
\text { connection } \\
\text { cross } \\
\text { beams }\end{array}$ & $\begin{array}{c}\text { rigid } \\
\text { connection } \\
\text { cross } \\
\text { beams }\end{array}$ & $\begin{array}{c}\text { conductor } \\
\text { with rigid } \\
\text { grippers }\end{array}$ \\
\hline $\begin{array}{l}\text { Installation } \\
\text { precision }\end{array}$ & $\begin{array}{c}\text { to } 20 \\
\text { mm }\end{array}$ & to $7.5 \mathrm{~mm}$ & to $6 \mathrm{~mm}$ & 0 \\
$\begin{array}{l}\text { Labor } \\
\text { input, \% }\end{array}$ & 100 & 75 & 60 & 45 \\
$\begin{array}{l}\text { Prime cost, } \\
\%\end{array}$ & 100 & 85 & 70 & 50 \\
$\begin{array}{l}\text { Duration, } \\
\%\end{array}$ & 100 & 60 & 50 & 20 \\
\hline
\end{tabular}

Table 3 shows that by the main indicators, the construction of buildings from block modules "Buk" (first option) has certain advantages.

Table 3. Comparative analysis of erection of PMB of different systems.

\begin{tabular}{lccc}
\hline Technical and economic indexes & \multicolumn{3}{c}{ Options of building } \\
\cline { 2 - 4 } & 1 & 2 & 3 \\
\hline Labor input per 1 sq. m of building & 4.50 & 6.20 & 4.60 \\
$\begin{array}{l}\text { The same per 1 ton of the building } \\
\text { weight }\end{array}$ & 11.10 & 13.20 & 14.70 \\
$\begin{array}{l}\text { Labor input of the building erection } \\
\text { per 1 sq. m }\end{array}$ & 8.60 & 10.80 & 12.30 \\
$\begin{array}{l}\text { Labor input of the manufacturing 1 } \\
\text { sq. } m\end{array}$ & $18,00-$ & 16.50 & 14.70 \\
$\begin{array}{l}\text { Labor input of transportation of a } \\
\text { 1-ton module }\end{array}$ & 4.00 & 2.40 & 2.80 \\
The same per 1 sq. m of building & 3.60 & 2.00 & 1.90 \\
\hline
\end{tabular}

Buildings made of prefabricated modular units from metal structures are appropriate to apply in regions with severe climatic conditions due to a number of technological and design advantages of modules:

- Ease of assembly of buildings from modules, no need for highly qualified personnel and supervision.
- Shorter time of erection and decommissioning of modular facilities at reduced costs of installation and dismantling of the building.

- The possibility of all-season erection due to the multipurpose nature of the design of individual modules allows erecting buildings in any weather conditions in flooded areas, which is especially important for seismic areas and regions with harsh climate.

- Strength, durability, mobility: as the design basis of modules is a collapsible metal frame, the objects made of them are earthquake-resistant, tolerate wind and snow loads, and if necessary, the building made of the modules can be quickly dismantled and erected elsewhere.

- The adaptability and versatility of modular structures allows erecting low-rise multi-purpose buildings (residential buildings, canteens, medical stations, schools, etc.) with the possibility of adding space and redevelopment of premises.

- The low cost: the cost of the finished modular buildings is much lower than the cost of concrete and brick buildings.

A survey of the state of 85 modular low-rise residential buildings (PMB) showed that most of the defects fall on the exterior walls, floors, finishes, and ventilation systems (up to $30 \%$ of defects), cracks in places of conjugation of walls and floors, peeling of the facing layer, and moisturizing of structures (15-20\% defects). The percentage of depreciation was determined in four monitoring periods: in $2.5 ; 5 ; 7.5$; and 10 years after the commissioning.

The influence of thermal and design characteristics of PMB on the technical parameters of the prefabricated buildings erection processes. To study the quantitative and qualitative patterns, we used the method of mathematical modeling, based on reproduction of the set of characteristics of the object through mathematics. This multi-factor model of normalizing the PMB thermal protective qualities was defined as:

$$
R_{0}=F\left\{\begin{array}{lllllll}
X_{1} X_{2} & X_{3} & X_{4} & X_{5} & X_{6} & X_{7} & X_{8}
\end{array}\right\}
$$

where $\mathrm{R}_{0}$ is the total thermal resistance of $\mathrm{PMB}$ structures;

$\mathrm{X}_{1}$ are the parameters of the module design / layer thickness, the type of insulation, the thermal insulation properties of materials; $\mathrm{X}_{2}$ is the type of building; $\mathrm{X}_{3}$ is the level of the house comfort; $\mathrm{X}_{4}$ is the design values of the 
outdoor temperature for a particular region; $\mathrm{X}_{5}$ is the heat consumption for the heating season; $\mathrm{X}_{6}$ is the type of heat transfer medium and the type of heat equipment; $\mathrm{X}_{7}$ is the quality of thermal insulation joints, the joints of modules; $\mathrm{X}_{8}$ is the estimated service life of the building.

There are two types of heat losses: due to heat transfer through the enclosing parts (wall, covers, floors, windows, doors), and by filtering the outside cold air through leaks and pores in the enclosing parts and their elements. In the engineering practice, heat losses that are due to heat transfer through the enclosing parts are determined by the formula:

$Q=\left\{\left(t_{i}-t_{e}\right) \cdot F\right\} / R_{o}$

and due to air filtering - by the formula:

$Q=C_{A} \cdot \gamma_{F} \cdot\left(t_{i}-t_{n}\right) \cdot F$

where $\mathrm{Q}$ is the heat loss, $\mathrm{W} ; t_{i} t_{e}$ is the calculated values of temperature of, respectively, internal and external air, ${ }^{\circ} \mathrm{C}$; $F$ is the enclosing parts' square, $\mathrm{m}^{2 i} R_{0}$ is the resistance of the enclosing parts to heat transfer, $\mathrm{m}^{2} \cdot{ }^{\circ} \mathrm{C} / \mathrm{W} ; C_{A}$ is the specific heat of storage capacity of the filtered air, $\mathrm{W} \cdot \mathrm{h} /$ $\mathrm{kg} .{ }^{\circ} \mathrm{C} ; \gamma_{F}$ is the amount of air to be filtered through $1 \mathrm{~m}^{2}$ of the enclosing parts, $\mathrm{kg} / \mathrm{m}^{2} \cdot \mathrm{h}$.

To obtain the raw data for mathematical modeling, we performed a preliminary experimental study of the PMB thermal characteristics on 10 semi-detached modular homes of the Buk 10M and Buk 10MM types for the $2 \mathrm{~V}$ climatic region of Russia with the following standard loads: the weight of the snow cover $-100 \mathrm{~kg} / \mathrm{m}^{2}$; the wind load - $23 \mathrm{~kg} / \mathrm{m}^{2}$; the temperature of the coldest five-day period $-29^{\circ} \mathrm{C}$; the ground resistivity $-1.5 \mathrm{kgf} / \mathrm{cm}^{2}$; the standard freezing depth $-1.4 \mathrm{~m}$; the fire resistance of the building - class $\mathrm{V}$.

A 2-storey 10-apartment house made of 28 threedimensional fully operational modules with the dimensions of $20.5 \times 24.0 \mathrm{~m}$ has a technical cellar, two residential floors with the height of $2.5 \mathrm{~m}$ in the light, with a pitched roof attic. The foundations of the building are of concrete ribbon type with longitudinal and transverse walls, supporting their bottom surface of the threedimensional modules around their perimeter.

The volume of the house $\mathrm{V}=3,225 \mathrm{~m}^{3 ;}$ the square $\mathrm{F}=$ $976 \mathrm{~m}^{2}$; the height is 2 floors; the weight is 20 tons.

The enclosing parts of the module (building) are a combined insulated structure. The modules' joints are welded.
Sealing of joints along the outer contour: sealing rubber and gluing. The sound reduction factor: $\mathrm{R}_{\mathrm{w}}=45-$ $50 \mathrm{~dB}$. Vapor barrier $\mathrm{S}_{\mathrm{d}}=130 \mathrm{~m}$; Waterproofing $\mathrm{m}_{\mathrm{y}}=$ 480,000 .

The calculated (nominal) thermal conductivity coefficients: $\mathrm{R}_{\mathrm{o} \text { (wall) }}=3.11 ; \mathrm{R}_{\mathrm{o} \text { (roof) }}=4.68 ; \mathrm{R}_{\mathrm{o} \text { (floor) }}=4.88 ; \mathrm{R}$ $\mathrm{o}$ (window) $=0.625$. The degree of prefabrication-95\%.

The vertical position of insulation in the enclosing parts required additional efforts to fix it and remove the defects such as: insulation setting and formation of air hollows.

Technical, economic, and social effectiveness of methods of technical diagnostics and monitoring of construction, reconstruction, and operation of prefabricated buildings.

The work method statement was analyzed and the results of calculations of various methods of work organization at the erection of the PMB complex were provided (Table 4), based on which the best option was selected, that would ensure reduction in the total duration of the erection of the PMB complex. In the provided example, the duration of the erection was reduced by 6 days, i.e. by $16.2 \%$, without involving additional resources. Comparison of various methods of work organization was carried out by the technique and programs of calculation proposed by Professor V. A. Afanasiev.

Table 4. Comparative analysis of the methods of work organization in the PMB erection

\begin{tabular}{|c|c|c|c|c|c|c|c|}
\hline 1 & $\begin{array}{l}\text { Names of work } \\
\text { organization } \\
\text { methods }\end{array}$ & $\mathrm{T}$ & K1 & $\mathrm{K} 2$ & K3 & K4 & K5 \\
\hline 2 & $\begin{array}{l}\text { The flow with } \\
\text { continuous } \\
\text { utilization of } \\
\text { resources }\end{array}$ & 37 & 0.810 & 0.806 & 1.000 & 0.634 & 0.811 \\
\hline 3 & $\begin{array}{l}\text { The flow with } \\
\text { continuous } \\
\text { development } \\
\text { of the scopes } \\
\text { of work }\end{array}$ & 31 & 0.967 & 0.811 & 0.654 & 1.000 & 0.843 \\
\hline 4 & $\begin{array}{l}\text { The flow with } \\
\text { critical works }\end{array}$ & 31 & 0.967 & 0.879 & 0.679 & 0.982 & 0.856 \\
\hline
\end{tabular}

$\mathrm{T}$ is the planned duration of the PMB erection, in days; $\mathrm{K} 1$ is the coefficient of the work timeliness; $\mathrm{K} 2$ is the coefficient of the work combination; $\mathrm{K} 3$ is the coefficient of the work continuity; $\mathrm{K} 4$ is the factor of continuity of 
the scope of work; K5 is the integral criterion of the work organization quality at $\mathrm{PMB}$ erection

The results of the scientific research performed by the author were used as the basis for developing a modernized type of PMB.

\section{Conclusion}

- A classification of methods of PMB erection from fully prefabricated modules with account of the methods of their completion and transportation to the erection site has been proposed.

- The technique for choosing a rational technology of $\mathrm{PMB}$ erection and determination of the best parameters of erection cranes and technological processes has been substantiated.

\section{References}

1. Adam FM, Bad'in GM. Features of installation of prefabricated buildings. Installation and special works in construction. 2001; 2:12-6.

2. Adam FM, Bad'in GM. Basic provisions of the methodology of surveying buildings and structures. St. Petersburg: Proceedings of the international scientific conference Actual problems of modern construction. 2004. p.101-3.

3. Afanas'ev A, Afonin I, Arutjunov S. Prefabricated buildings erection technique. Association Building Universities. 2007.

4. Allen E, Iano J. Fundamentals of building construction: Materials and methods. J Wiley and Sons. 2004.
5. Bad' in GM, Sychev SA. Assembled mansard roof erection technique. 2009.

6. Bad'in GM, Sychev SA. Advanced technologies of buildings erection and reconstruction. BHV-Saint Petersburg Publishing. 2013.

7. Day A. When modern buildings are built offsite. Building Engineer. 2011; 86(6):18-9.

8. Fudge J, Brown S. Prefabricated modular concrete construction. Building Engineer. 2011; 86(6):20-1.

9. Head PR. Construction materials and technology: A look at the future. Proceedings of the ICE - Civil Engineering. 2001; 144(3):113-8.

10. Knaack U, Chung-Klatte Sh, Hasselbach R. Prefabricated systems: Principles of construction. De Gruyter. 2012.

11. Lawson RM, Richards J. Modular design for high-rise buildings. Proceedings of the ICE - Structures and Buildings. 2010; 163(3):151-64.

12. Nadim W, Goulding JS. Offsite production in the UK: The Way forward? A UK construction industry perspective. Construction Innovation: Information, Process, Management. 2010; 102:181-202.

13. Swamy RN. Holistic design: Key to sustainability in concrete construction. Proceedings of the ICE - Structures and Buildings. 2001; 146(4):371-9.

14. Sychev SA. Technology of installation of pre-fabricated structures. Bulletin of Civil Engineers. 2008; 329:28-30.

15. Sychev SA. Mansard roof accelerated erection technique. LAP LAMBERT Academic Publishing. 2008.

16. Wang Y, Huang Z, Heng L. Cost-effectiveness assessment of insulated exterior wall of residential buildings in cold climate. Int J Proj Manag. 2007; 252:143-9. 